\title{
PEMBERDAYAAN IBU-IBU PKK DESA PENGEMPON KECAMATAN SRUWENG KABUPATEN KEBUMEN MELALUI PELATIHAN SAFETY DAN EFISIENSI PENGGUNAAN LISTRIK RUMAH TANGGA
}

\author{
Syahid $^{1)}$, Ari Santoso ${ }^{2}$, Aji Hari Riyadi ${ }^{3}$, Yusnan Badruzzaman ${ }^{4}$ \\ 1,2,3,4 Dosen Jurusan Teknik Elektro, Politeknik Negeri Semarang, Jalan. Prof. H.Sudarto Tembalang, \\ Semarang, 50269 \\ E-mail:syahidkbm@gmail.com
}

\begin{abstract}
Electricity consumption in Indonesia in recent years has increased by $10-15 \%$ per year. There was an increase in electricity in the household sector, from about 24,000 SBM (units of barrel oil) in the year 1999 to 33,000 SBM in 2003. Accidents because electricity is also very large because of electrical problems. The potential of energy conservation and safety of electrical energy use in all sectors has a considerable improvement opportunity. Pengempon Village Sruweng Subdistrict is one of the villages in Kebumen district has activities for mothers who belong to the PKK. PKK mothers in this village are mostly housewives that every day have to take care of households including also regulating the use and payment of household electricity. The use of electrical appliances such as fans, refrigerators, dispensers, Rice cookers besides lamps become a contributor to large energy consumption. Basic cost electricity (TDL) will further increase the expenditure of electricity payments for PKK mothers in this Pengempon village and also problems in terms of safety of electricity use. Often mothers do not know and accidentally hold or contact with electricity is very dangerous. The goal of community service is to contribute to solve problems in energy efficiency and safety of electrical energy use for PKK mothers. The special Target of this devotion is (1) electrical energy efficiency; (2) Safety of electrical energy use. Results obtained after carrying out the activities of this dedication is the increasing knowledge of PKK mothers about the efficiency and safety of the use of electricity energy
\end{abstract}

Keywords: PKK mothers, Pengempon Village, energy efficiency, safety, electrical energy

\begin{abstract}
Abstrak
Konsumsi listrik di Indonesia dalam beberapa tahun terakhir mengalami peningkatan 10 - $15 \%$ per tahun. Terjadi peningkatan listrik di sektor rumah tangga, dari sekitar 24.000 SBM (Satuan Barel Minyak) di tahun 1999 menjadi 33.000 SBM pada tahun 2003. Kecelakan karena listrik juga sangat besar karena masalah kelistrikan. Potensi konservasi energi dan safety penggunaan energi listrik di semua sektor memiliki peluang peningakatan yang cukup besar.Desa Pengempon Kecamatan Sruweng merupakan salah satu desa di Kabupaten Kebumen memiliki kegiatan untuk Ibu-ibu yang tergabung dalam PKK. Ibu-ibu PKK di desa ini sebagian besar adalah ibu rumah tangga yang setiap harinya harus mengurusi rumah tangga termasuk juga mengatur pemakaian dan pembayaran listrik rumah tangga. Penggunaan peralatan listrik seperti kipas angin, Kulkas, Dispenser, Rice Cooker disamping lampu menjadi penyumbang konsumsi energi yang besar. Kenaikan Tarif dasar Listrik (TDL) akan semakin menambah pengeluaran pembayaran listrik untuk ibu-ibu PKK di Desa Pengempon ini dan juga masalah dalam hal safety penggunaan listrik. Seringkali ibu-ibu tidak tahu dan tidak sengaja memegang atau kontak dengan listrik yang sangat berbahaya.Tujuan Pengabdian pada Masyarakat ini adalah berkontribusi menyelesaikan permasalahan pada bidang efiseiensi energi dan safety penggunaan energi listrik untuk ibu-ibu PKK tersebut.Target khusus Pengabdian ini adalah (1) efisiensi energi listrik; (2) safety penggunaan energi listrik. Hasil yang didapatkan setelah melaksanakan kegiatan pengabdian ini yaitu semakin bertambahnya pengetahuan ibu - ibu PKK mengenai efisiensi dan safety penggunaan enenrgi listrik
\end{abstract}

Kata Kunci: Ibu-Ibu PKK,Desa Pengempon,efisiensi energi, safety,energi listrik 


\section{PENDAHULUAN}

Data tentang kecelakaan yang diakibatkan karena penggunaan enenrgi listrik sangat besar. Berdasar laporan National Fire Protection Association (NPFA), dalam kurun waktu 2007-2011, 13\% dari seluruh kasus kebakaran bangunan di Amerika disebabkan oleh kegagalan listrik (electrical failure). Sepanjang tahun 2011 sendiri dilaporkan telah terjadi 47,000 kasus kebakaran oleh listrik yang mengakibatkan 418 orang meninggal dunia 1.570 orang mengalami cedera/luka-luka Kerugian material senilai \$1,4 milyar.Hampir setengah (48\%) dari kasus kebakaran oleh listrik tersebut bermula dari peralatan penerangan dan distribusi listrik. Sisanya, berasal dari kipas angin (6\%), pengering $(6 \%)$, pemanas ruangan $(4 \%)$, pendingin ruangan $(4 \%)$, pemanas air $(3 \%)$, dan lain-lain (29\%). Analisis lebih lanjut mengungkapkan bahwa peralatan penerangan dan distribusi listrik yang menyebabkan terjadinya kebakaran tersebut bisa dikelompokkan sebagai berikut: $63 \%$ berasal dari sistem perkabelan, $20 \%$ berasal dari lampu dan fitting lampu, $11 \%$ berasal dari terminal dan steker, 6\% berasal dari transformator dan power supply ( Jurnal K3LH 2015). Dari uraian di atas jelaslah kiranya bahwa diperlukan kehati-hatian dengan masalah perlistrikan, baik di rumah maupun di kantor.

Desa Pengempon, Kecamatan Sruweng, Kabupaten Kebumen berada sekitar 150 km dari ibu kota provinsi Jawa Tengah mempunyai wilayah seluas 273 hektar. Kondisi wilayahnya merupakan daerah perbukitan dengan infrastruktur jalan yang sebagian masih jalan desa tidak beraspal. Jumlah penduduk :3.734 jiwa dengan kepala keluarga : $1.040 \mathrm{KK}$, terdiri dari penduduk laki-laki : 1.982 jiwa, perempuan: 1.752 jiwa. Jumlah warga pada usia produktif 18 - 24 tahun : 955 jiwa. Sebagian besar dari penduduk desa adalah petani dan tingkat golongan ekonomi menengah kebawah. Kegiatan bidang ekonomi yang ada dan berkembang di Desa Pengempon ini adalah UKM Roti.

Pembinaan Kesejahteraan Keluarga, disingkat PKK, adalah organisasi kemasyarakatan yang memberdayakan wanita untuk turut berpartisipasi dalam pembangunan Indonesia. Gerakan PKK bertujuan memberdayakan keluarga untuk meningkatkan kesejahteraan menuju terwujudnya keluarga yang beriman dan bertaqwa kepada tuhan yang maha esa, berakhlak mulia dan berbudi luhur, sehat sejahtera, maju dan mandiri, kesetaraan dan keadilan gender serta kesadaran hukum dan lingkungan. Anggota Tim Penggerak PKK adalah para relawan, yang tidak menerima gaji, baik perempuan maupun lakilaki, yang menyediakan sebagian dari waktunya untuk PKK. Walaupun Sasaran PKK adalah keluarga, khususnya ibu rumahtangga, perempuan, sebagai sosok sentral dalam keluarga. Ia tidak hanya mengurus soal kehidupan rumahtangganya dan mengasuh 
anak saja. Banyak diantara ibu rumahtangga yang membantu suami disawah, bahkan berusaha menambah pendapatan keluarga dengan berjualan.

Dari pemetaan sebaran masyarakat yang ada di Desa Pengempon, Kecamatan Sruweng, Kabupaten Kebumen, didapatkan jumlah perempuan 46.92 \% jumlah penduduk yang ada. Jumlah ini dikelompokan lagi pada usia 19-45 tahun dengan latar pendidikan minimal SD, SMP dan maksimal SMU. Untuk lebih memudahkan karena keterbatasan penyelenggaraan dalam pemilihan peserta yang akan dipilih dari perwakilan tingkat Rukun Tetangga yang ada. Diharapkan dengan perwakilan tersebut nantinya akan dapat ditularkan pengetahuannya pada masyarakat yang lain di tempatnya masing-masing.

\section{METODE PELAKSANAAN}

Metode dan kegiatan untuk menyelesaikan persoalan mitra sebagai berikut :

\begin{tabular}{|c|c|c|}
\hline No & Metode & Kegiatan \\
\hline 1. & $\begin{array}{l}\text { Desain untuk implementasi } \\
\text { Efisiensi energi, sosialisasi } \\
\text { keselamatan penggunaan } \\
\text { peralatan listrik }\end{array}$ & $\begin{array}{l}\text { a. Survei dan identifikasi } \\
\text { b. Tabulasi dan analisa data } \\
\text { c. Membuat model efisiensi energi } \\
\text { d. implementasi efisiensi energi }\end{array}$ \\
\hline 2. & Penataan Penjaminan Mutu & $\begin{array}{l}\text { a. Pemasangan lampu hemat energi } \\
\text { b. Pemasangan ELCB untuk keamanan } \\
\text { kebocoran listrik } \\
\text { c. Evaluasi penerimaan user } \\
\text { d. Pembuatan standar SOP efisiensi energi dan } \\
\text { safety }\end{array}$ \\
\hline 3. & $\begin{array}{l}\text { Pemanfaatan sistem hemat } \\
\text { energi dan safety }\end{array}$ & $\begin{array}{l}\text { a. Pelatihan dan sosialisasi } \\
\text { b. Pembinaan } \\
\text { mitra c. Temu } \\
\text { lapang } \\
\text { d. Pendampingan mitra }\end{array}$ \\
\hline
\end{tabular}




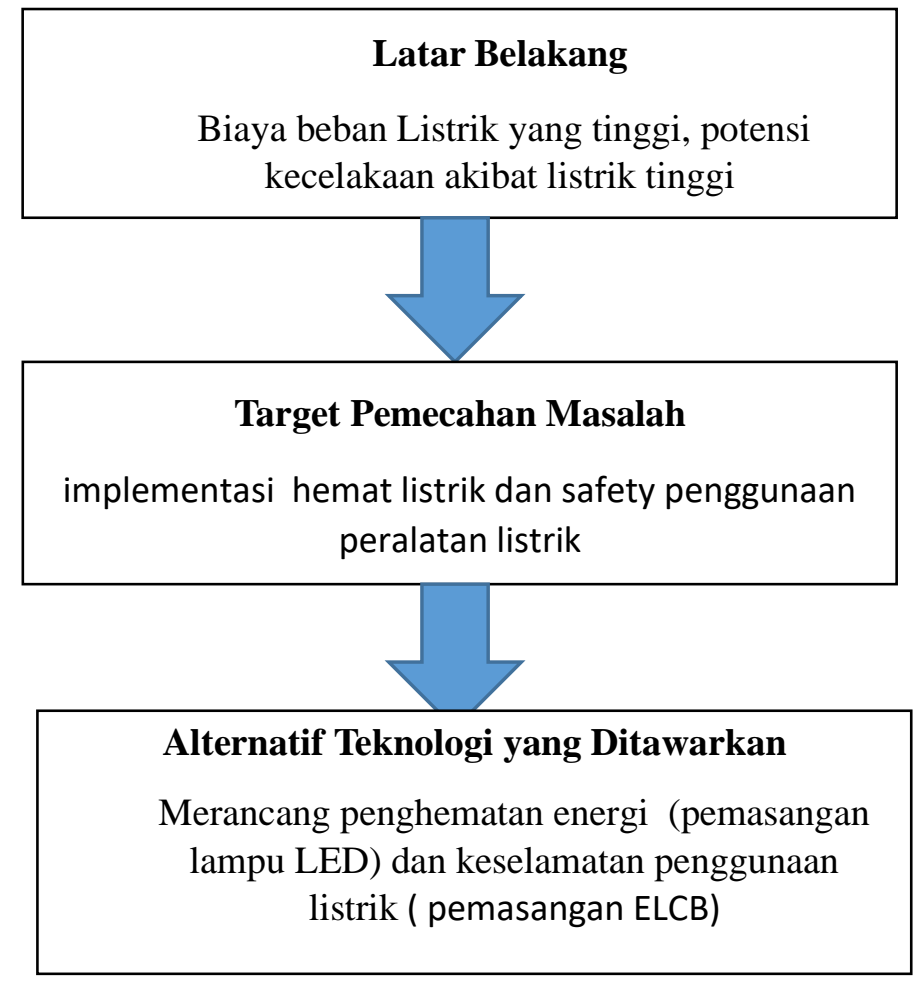

HASIL DAN PEMBAHASAN

Penggunaan lampu hemat energi sudah sejak lama mulai di kembangkan.Perkembangan lampu hemat energi bisa dilihat apada gambar 1 dibawah ini :

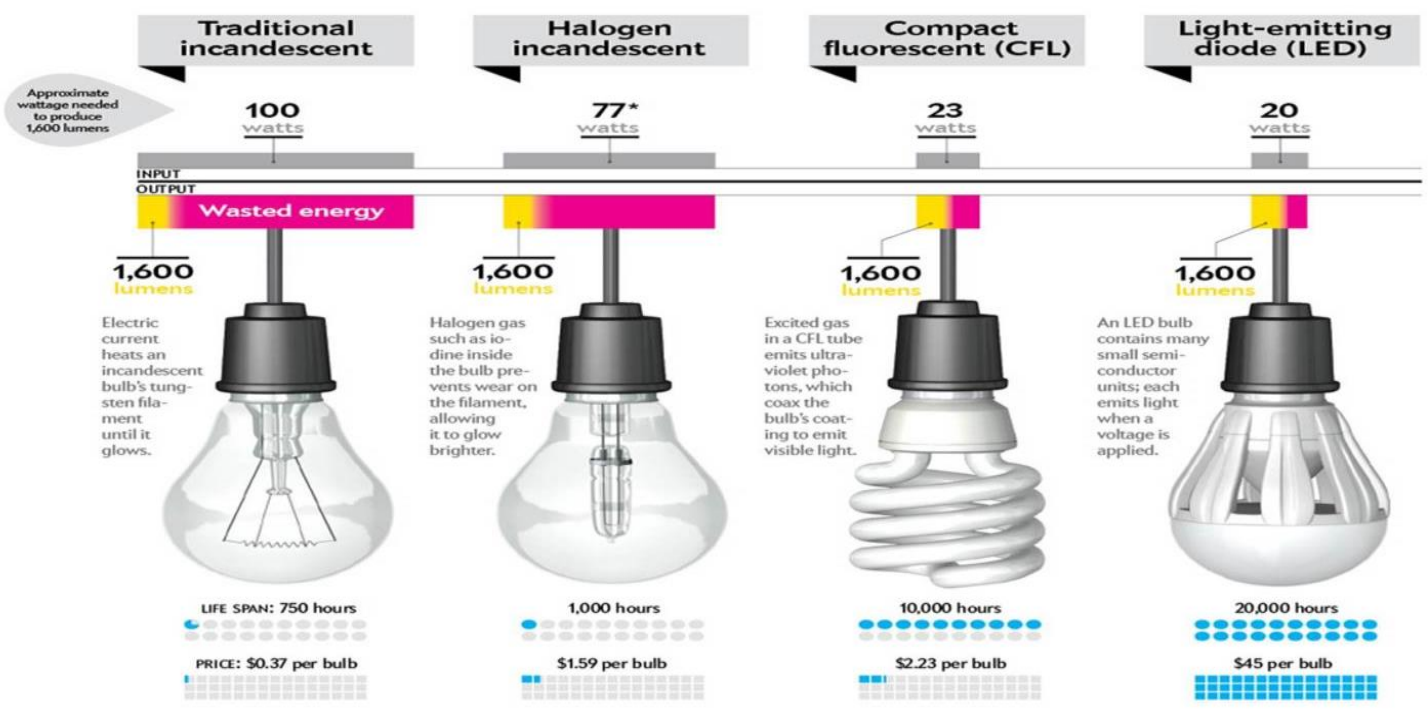

Gambar 1 Perkembangan Pemakaian Lampu 
Dalam memilih lampu yang harus diperhatikan pada dasarnya adalah konsumsi listrik (daya, watt) dan intensitas cahaya yang dihasilkan (light output, lumens).Ukuran ruangan juga menjadi salah satu faktor yang harus diperhitungkan dalam memilih lampu. Ruangan yang kecil membutuhkan lampu dengan kapasitas yang tidak terlalu besar, sedangkan untuk ruangan yang besar membutuhkan lampu dengan kapasitas yang besar.

Perbandingan daya dan light output lampu LED dan LHE dan Lampu Pijar.

Tabel 1 . Tabel Konversi ( Energi Listrik menjadi Energi Cahaya ) LED, LHE, dan Lampu Pijar

\begin{tabular}{|c|c|c|c|c|c|c|}
\hline & \multicolumn{2}{|c|}{ LED } & \multicolumn{2}{|c|}{ Lampu Hemat Energi } & \multicolumn{2}{|c|}{ Lampu Pijar } \\
\hline $\begin{array}{c}\text { Penghematan } \\
\text { Energi }\end{array}$ & \multicolumn{2}{|c|}{$90 \%$} & \multicolumn{2}{|c|}{$70 \%$} & \multicolumn{2}{|c|}{$10 \%$} \\
\hline \multirow{5}{*}{$\begin{array}{l}\text { Lumen - } \\
\text { Satuan } \\
\text { Cahaya }\end{array}$} & $\begin{array}{c}3 \\
\text { watt }\end{array}$ & $270 \mathrm{~lm}$ & 5 watt & $275 \mathrm{~lm}$ & 25 watt & $250 \mathrm{~lm}$ \\
\hline & $\begin{array}{c}5 \\
\text { watt }\end{array}$ & $450 \mathrm{~lm}$ & 8 watt & $440 \mathrm{~lm}$ & 40 watt & $400 \mathrm{~lm}$ \\
\hline & $\begin{array}{c}8 \\
\text { watt }\end{array}$ & $720 \mathrm{~lm}$ & 12 watt & $720 \mathrm{~lm}$ & 75 watt & $750 \mathrm{~lm}$ \\
\hline & $\begin{array}{c}11 \\
\text { watt }\end{array}$ & $1.050 \mathrm{~lm}$ & 18 watt & $1.080 \mathrm{~lm}$ & $\begin{array}{l}100 \\
\text { watt }\end{array}$ & $1.000 \mathrm{~lm}$ \\
\hline & $\begin{array}{c}14 \\
\text { watt }\end{array}$ & $1.400 \mathrm{~lm}$ & 23 watt & $1.380 \mathrm{~lm}$ & $\begin{array}{l}140 \\
\text { watt }\end{array}$ & $1.400 \mathrm{~lm}$ \\
\hline $\begin{array}{l}\text { Daya Listrik ( } \\
\text { watt ) }\end{array}$ & & 11 & & & & \\
\hline $\begin{array}{l}\text { Pemakaian } \\
\text { Listrik } 15.000\end{array}$ & & KWh & & $\mathrm{Wh}$ & 1.5 & $\mathrm{KWh}$ \\
\hline
\end{tabular}




\begin{tabular}{|c|c|c|c|}
\hline jam & & \\
\hline $\begin{array}{c}\text { Biaya Listrik } \\
15.000 \text { jam } \\
\begin{array}{c}\text { Rp. } 1.352 / \\
\text { KWh })\end{array}\end{array}$ & Rp. 223.080,- & Rp. 365.040,- & Rp. 2.028.000,- \\
\hline $\begin{array}{c}\text { Panas yang } \\
\text { dipancarkan }\end{array}$ & $\begin{array}{c}\text { Rendah } \\
\text { (3.4 Btu/jam })\end{array}$ & $\begin{array}{c}\text { Sedang } \\
\text { (30 Btu/jam })\end{array}$ & $\begin{array}{c}\text { Tinggi } \\
\text { (85 Btu/jam })\end{array}$ \\
\hline
\end{tabular}

* berdasarkan peraturan Menteri ESDM RI No. 19 thn 2014 Tarif Rumah Tangga R-1 2.200 VA

Untuk safety atau keamanan penggunaan energi listrik dipasang ELCB (Earth leakage Curent Breakers). ELCB di sebut juga dengan istilah RCD (Residual Current Device). adapun kegunaan ELCB adalah sebagai pengaman pada suatu rangkaian instalasi listrik. Maka penting untuk memasang ELCB dan pada instalasi listrik. ELCB akan secara otomatis mendeteksi kebocoran arus listrik dan kontak body. Di indonesia sendiri pemasangan ELCB pada instalasi listrik rumah masih sangat jarang di gunakan, kemungkinan besar karena harga ELCB yang cukup mahal.

Rangkaian instalasi ELCB seperti gambar 2 dibawah ini 


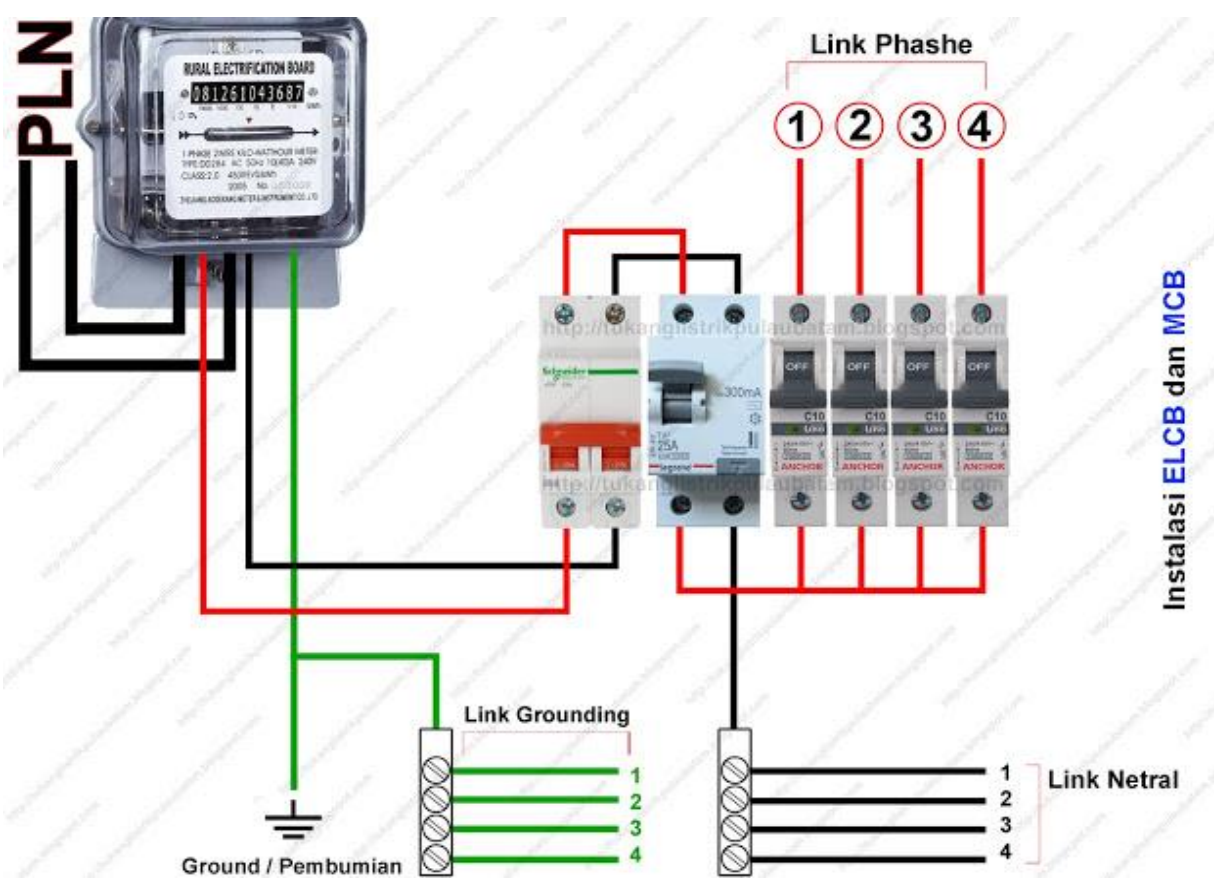

Gambar 2 . Rangkaian instalasi ELCB

Dokumentasi pelaksanaan kegiatan pada saat pelatihan seperti gambar 3 berikut

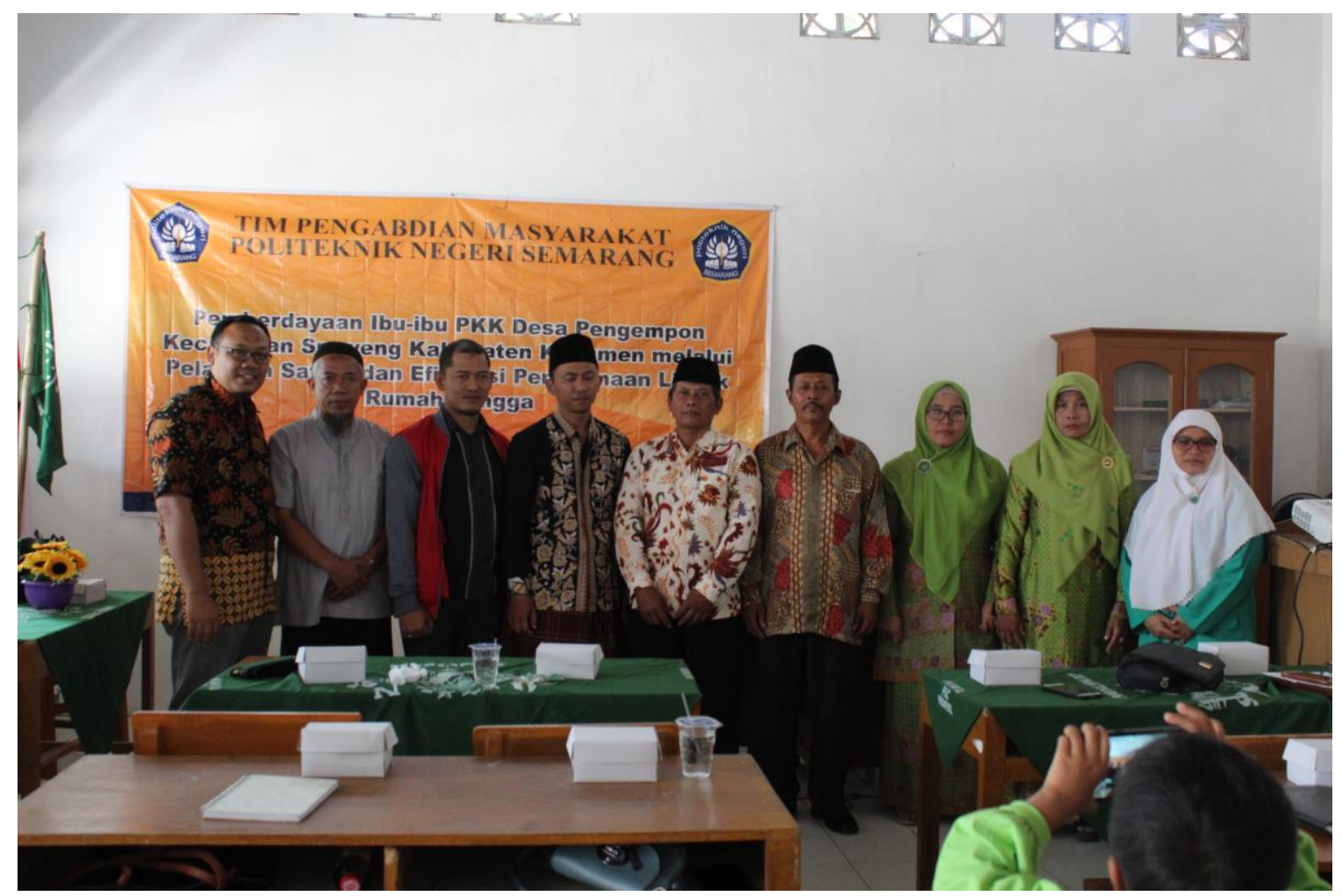




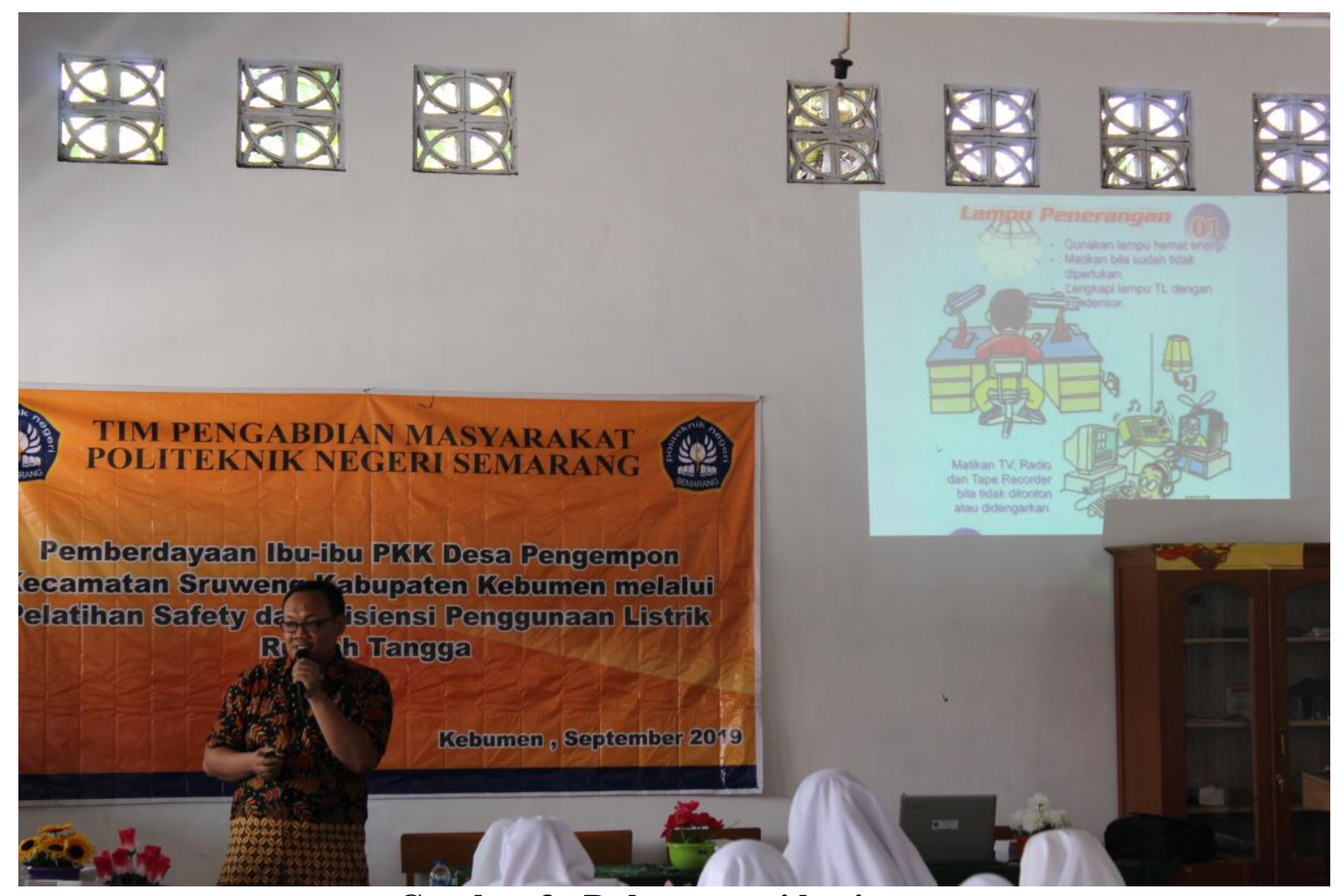

Gambar 3 . Dokumentasi kegiatan

\subsection{Dampak Yang Diperoleh Mitra}

Dampak yang di dapatkan dari kegiatan Pemberdayaan Ibu-ibu PKK Desa Pengempon Kecamatan Sruweng Kabupaten Kebumen melalui Pelatihan Safety dan Efisiensi Penggunaan Listrik Rumah Tangga adalah sebagai berikut :

a.Dapat mengimplementasikan efisiensi energi di Desa Pengempon Kecamatan Sruweng Kabupaten Kebumen

b. Dapat melakukan safety energy listrik.

\section{KESIMPULAN}

Berdasarkan kegiatan pengabdian yang sudah dilakukan dapat disimpulkan :

1. Pelaksanaan kegiatan pengabdian kepada masyarakat kegiatan Pemberdayaan Ibu-ibu PKK Desa Pengempon Kecamatan Sruweng Kabupaten Kebumen melalui Pelatihan Safety dan Efisiensi Penggunaan Listrik Rumah Tangga berjalan dengan lancar dan sukses. 
2. Pemberdayaan Ibu-ibu PKK Desa Pengempon Kecamatan Sruweng Kabupaten Kebumen melalui Pelatihan Safety dan Efisiensi Penggunaan Listrik Rumah Tangga berhasil dilakukan. Efisiensi energy listrik untuk lampu yaitu lampu lama diganti dengan lampu LED.

3. Safety pemakaian energi listrik di Desa Pengempon Kecamatan Sruweng Kabupaten Kebumen menggunakan perangkat ELCB dan pelatihan keamanan penggunaan energy listrik

\section{DAFTAR PUSTAKA}

[1] Andika Sutedjo , 2010, Saklar Cerdas Hemat Energi, Jakarta,

[2] Energy Management Indonesia (Persero), 2008, Ayo Berhemat BBM dan Listrik, PT.Energy Management Indonesia (Persero),Jakarta

[3] Rianto.A. 2007. Audit Energi dan Analisis Peluang Penghematan Konsumsi Energi pada Sistem Pengkondisian Udara di Hotel Santika Premiere Semarang. (tesis). Semarang: UNNES

[4] Dirjen ketenagalistrikan ESDM, 2016, Keselamatan dan Pemasangan Instalasi Listrik Voltase Rendah untuk Rumah Tangga (PUIL), jakarta

[5]. http://iesr.or.id/2012/04/workshop-efisiensi-energi-di-industri-kecil-menengah-ikm/

[6] http://www.bjp.web.id/2016/04/electrical-safe-work-standard-standar.html

[7] http://electrical-engineering-portal.com/what-is-the-difference-between-mcb-mccbelcb-and-rccb

[8] https://en.wikipedia.org/wiki/Earth_leakage_circuit_breaker 